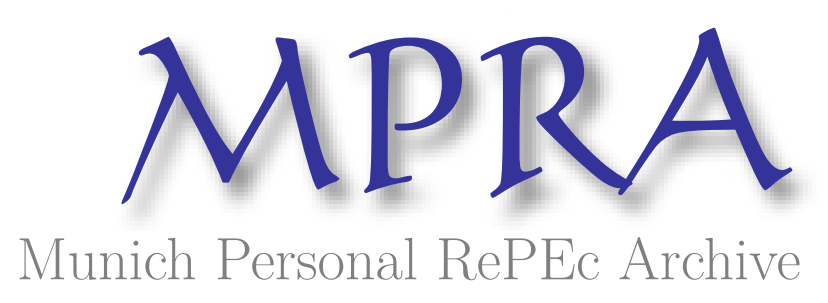

\title{
The Choice of Technology and Economic Geography
}

Zhou, Haiwen

4 December 2021

Online at https://mpra.ub.uni-muenchen.de/110939/

MPRA Paper No. 110939, posted 07 Dec 2021 14:16 UTC 


\title{
The Choice of Technology and Economic Geography
}

\author{
Haiwen Zhou
}

\begin{abstract}
Empirical evidence shows that firms located in regions with larger population size are on average larger and more productive. To explain this empirical observation, firms producing intermediate goods are assumed to choose their technologies with different levels of fixed and marginal costs. In this general equilibrium model of economic geography, intermediate good producers engage in oligopolistic competition. The model is tractable and leads to interesting and analytical results. An intermediate good producer in the region with a higher population produces a higher level of output and has a lower marginal cost of production regardless of the existence of regional trade. With regional trade, if a worker moves from the region with a lower number of workers to the region with a higher number of workers, intermediate good producers in both regions choose less advanced technologies.
\end{abstract}

Keywords: Technology choice, economic geography, international trade, increasing returns, oligopoly

JEL Classification Numbers: F12, R12, L13, D43, O14

\section{Introduction}

Empirical evidence shows that firms located in larger metropolitan areas are on average larger and more productive. For example, Holmes and Stevens (2002) find that manufacturing plants located in areas where an industry concentrates are substantially larger than those in the same industry outside such areas. Using U. S. data, Wheeler (2006) shows that average plant size increases significantly with an industry's employment in a metropolitan area. Using Chinese data, $\mathrm{Li}, \mathrm{Lu}$, and $\mathrm{Wu}$ (2012) establish a positive relationship between industry agglomeration and firm size. Also, large plants on average are more productive (Oi and Idson, 1999).

The size and productivity of a firm are not exogenously given, and they are likely to be affected by a firm's technology, which will be determined by fundamental factors such as population size in a region (Combes et al., 2012). ${ }^{1}$ That is, firms choose their technologies based on their levels of outputs, which are affected by regional population sizes. There are numerous examples of firms' choices of technologies. First, Porter (1990, p. 97) discusses choices of printers

\footnotetext{
${ }^{1}$ There are two main explanations that on average firms are more productive in larger cities: firm selection because a larger market size leads to a higher degree of competition and less efficient firms would be forced to exit, and agglomeration economies. Using French data, Combes et al. (2012) find that firm selection cannot explain spatial productivity differences.
} 
by firms. There are three types of printers, and the most expensive one is the fastest and is suitable for large volume printing such as printing newspapers. The costs of purchasing printers are fixed costs and an increase in the level of fixed costs leads to a decrease in the marginal cost of printing. Second, Prendergast (1990) discusses the tradeoff between fixed and marginal costs in three industries: nuts and bolts, iron founding, and machine tools. In those industries, technologies with higher fixed costs have lower marginal costs of production. Prendergast shows that a firm's output determines its choice of technology: a higher level of output leads to the adoption of technologies with higher fixed costs of production. Finally, Levinson (2006) discusses the adoption of containers and the choice of technology in the transportation sector. The adoption of containers was one of the most important innovations in the transportation sector in the twentieth century. Adoption of containers began in the 1950s. At that time, the loading and unloading of cargos were handled by longshoremen and were labor-intensive. With high wage rates, marginal costs were high. Because specially designed cranes, containerships, and container ports had to be built, the adoption of containers led to sharp rises in fixed costs in the transportation sector. However, compared with the technology of using longshoremen to load and unload cargos, marginal costs of loading and unloading decreased sharply.

In models of economic geography, it is frequently assumed that firms in different regions use the same technology by specifying that firms have the same fixed and marginal costs of production. Incorporating a firm's technology choice will be useful in explaining the empirical evidence that firms in larger cities are on average more productive. One interesting question about technology choice is the following. Suppose a worker moves from a region with a lower population to a region with a higher population. After this labor movement, firms in the two regions may adjust their technologies. Will this labor mobility lead to an increase in the degree of technological difference between the two regions in the sense that firms in the region with a higher population choose more advanced technologies while those in the region with a lower population choose less advanced technologies? The wage rate in a region can be directly related to a firm's technology and a larger technology gap between regions may induce a larger wage gap. If this larger wage gap increases a worker's utility in the region with a higher population relatively, remaining workers in the region with a lower population have incentives to move to the region with a higher population. That is, will the choice of technology work as a channel for the concentration of economic activities? 
In this paper, we show that the incorporation of technology choice into a general equilibrium model of economic geography can explain the empirical observation that firms located in areas with large population size are on average larger and more productive. In this model, farmers and workers live in two regions. Individuals consume an agricultural good and a manufactured good. The manufactured good is produced by intermediate goods and intermediate good producers choose technologies to maximize their profits. Different technologies differ in their fixed and marginal costs. Like Spencer and Brander (1983), Venables (1985), Qiu and Zhou (2007), Chen and Shieh (2011), and Neary (2016), intermediate good producers engage in oligopolistic competition. ${ }^{2}$ The motivation of oligopoly as the type of market structure is as follows. When firms engage in oligopolistic competition, the number of firms producing the same intermediate input can be affected by fundamental factors like population size. Oligopoly as a type of market structure can be used to address how a firm's level of output changes with fundamental factors (Neary, 2001). When a firm's output changes, its level of technology can change correspondingly. Thus, a firm's technology choice can be conveniently addressed when firms engage in oligopolistic competition.

With regional trade, we show that the region with a higher number of workers (region 1) exports the manufactured good to the other region (region 2) and imports the agricultural good. Consistent with empirical observation, we show that an intermediate good producer in the region with a higher number of workers produces a higher level of output and have a lower marginal cost of production regardless of the existence of regional trade or not.

Interestingly, the incorporation of the choice of technology does not increase the wage gap or technology gap between the two regions. If a worker moves from the region with a lower number of workers to the other one, surprisingly intermediate good producers in both regions choose less advanced technologies, but the wage ratio between the two regions will not change. A firm's technology choice is determined by its level of output, which depends on market size (Zhou, 2004). Since market for the manufactured good is integrated for the two regions, market size is a weighted average of population of the two regions. When a worker moves from region 2 to region 1, market size decreases and the "total effective output" of the manufactured good (which is the sum of

\footnotetext{
${ }^{2}$ Oligopoly has been an important type of market structure for developed countries such as the United States since the Second Industrial Revolution because the existence of significant fixed costs in production leads to increasing returns to scale (Chandler, 1990). Thus, large firms have cost advantages over small firms and perfect competition will not prevail.
} 
regional outputs weighted by transportation costs) from the two regions decreases, thus intermediate good producers choose less advanced technologies. The wage ratio will not change because the number of intermediate good producers will adjust in both regions. When region 1 has a higher number of workers, the number of intermediate good producers increases in this region. When region 2 has a lower number of workers, the number of intermediate good producers in region 2 decreases. Overall, worker mobility will not widen the technology difference and the wage ratio between the two regions. That is, while the choice of technology as a channel of industry concentration seems intuitive, how this mechanism works is not as straightforward as we have expected.

In a seminal paper, Krugman (1991) studies a model of economic geography in which firms engage in monopolistic competition. Nocco (2005) introduces differences in technologies used by firms located at different regions and studies how these differences may evolve over time according to the level of international economic integration. This line of literature is synthesized in Fujita, Krugman and Venables (1999). Models of economic geography in which firms engage in oligopolistic competition have been studied by Combes (1997), Belleflamme, Picard, and Thisse (2000), Zhou (2007), Combes and Lafourcade (2011), Dewit, Leahy, and Montagna (2013). ${ }^{3}$ This paper contributes to the literature by incorporating technology choice into a general equilibrium model of economic geography in which firms engage in oligopolistic competition.

The plan of the paper is as follows. Section 2 specifies the model and establishes the equilibrium when there is no regional trade. Except that intermediate good producers engage in oligopolistic competition rather than monopolistic competition and choose technologies, the specifications of this model and the questions addressed follow those in Krugman (1991) closely. Section 3 studies whether the equilibrium with equal distribution of workers in the two regions without regional trade is stable. Section 4 revisits the equilibrium when there is regional trade. Section 5 examines the impact of worker movement under regional trade. Section 6 concludes. The Appendix contains the proofs of all propositions.

\footnotetext{
${ }^{3}$ Combes (1997) assumes that markets for manufactured goods are segregated. Belleflamme, Picard, and Thisse (2000) allow for technological spillovers among firms. Zhou (2007) assumes that markets for manufactured goods are integrated. Combes and Lafourcade (2011) study a multi-region and multi-industry model. Dewit, Leahy, and Montagna (2013) address the use of labor standard as a commitment device when strategic interaction among firms is important.
} 


\section{Regions in autarky}

There are two regions: region 1 and region 2. Subscripts of variables are used to denote regions. A region has farmers and may have workers. Farmers are specific to the agricultural sector and cannot move between the regions (Krugman, 1991). All farmers and workers in the two regions have the same preferences. Also, the two regions have access to the same set of agricultural and manufacturing technologies. In this section, we study the equilibrium when there is no regional trade. We focus on the study of region 1. First, we study a consumer's utility maximization. Second, we examine profit maximization of a final good producer and that of an intermediate good producer. Third, we set up market clearing conditions, including labor market and goods markets clearance. Finally, we establish the autarky equilibrium.

\subsection{Utility maximization}

A consumer derives utility from two goods: an agricultural good and a manufactured good. A consumer's consumption of the agricultural good is $C^{A}$ and her consumption of the manufactured good is $C^{M}$. For the constant $\alpha \in(0,1)$, her utility function is $U=\left(C^{A}\right)^{\alpha}\left(C^{M}\right)^{1-\alpha}$. With this homothetic utility function, utility maximization requires that a consumer spends $\alpha$ percent of income on the agricultural good and 1- $\alpha$ percent of income on the manufactured good.

\subsection{The agricultural sector}

The agricultural good is produced by farmers. The number of farmers in region 1 is $T_{1}$, which is exogenously given. There are constant returns to scale in the agricultural sector. Without loss of generality, each farmer in the agricultural sector produces one unit of the agricultural good. Thus, the level of agricultural output in region 1 is $T_{1}$. The agricultural good is used as the numeraire: $p^{A}=1$. With this normalization, the income of a farmer is one.

\subsection{The manufacturing sector}

The manufactured good is produced by combining a continuum of intermediate goods indexed by a number $\omega \in[0,1]$ (He and Yu, 2015; Tabuchi, Thisse, and Zhu, 2018). ${ }^{4}$ The price of an intermediate good $\omega$ in region 1 is $p_{1}(\omega)$. All intermediate goods have the same costs of

\footnotetext{
${ }^{4}$ Tabuchi, Thisse and Zhu (2018) analyze how reductions due to technological progress in the costs of producing and trading goods interact with the various costs borne by migrants who can be mobile between regions.
} 
production and enter the production of the manufactured good in a symmetric way. ${ }^{5}$ Except the usage of intermediate goods, the manufactured good is produced without incurring any additional cost. Let $\delta$ denote a positive constant not smaller than one. If the amount of intermediate good $\omega$ used in the production of the manufactured good is $q^{M}(\omega)$, then the manufactured output is $\left.\left(\int_{0}^{1} q^{M}(\omega)\right)^{\frac{\delta-1}{\delta}} d \omega\right)^{\frac{\delta}{\delta-1}}$. The price of the manufactured good is $P$. Firms producing the manufactured good engage in perfect competition. A firm producing the manufactured good tries to maximize profit $\left.P\left(\int_{0}^{1} q^{M}(\omega)\right)^{\frac{\delta-1}{\delta}} d \omega\right)^{\frac{\delta}{\delta-1}}-\int_{0}^{1} p_{1}(\omega) q^{M}(\omega) d \omega$. Thus, for $i=1,2$ denoting the two regions, a manufactured good producer's profit maximization implies that the elasticity of demand of an intermediate good is constant: $\frac{p_{i}}{q^{M}(\omega)} \frac{\partial q^{M}(\omega)}{\partial p_{i}}=-\delta$. Also, the relationship between the price of the manufactured good and prices of intermediate inputs is $P=\left[\int_{0}^{1} p_{1}(\omega)^{1-\delta} d \varpi\right]^{\frac{1}{1-\delta}}$.

To produce each intermediate good, there is a continuum of technologies with different fixed and marginal costs indexed by a number $n \in R_{+}^{1}$ (Zhou, 2004, 2009, 2019, 2021; Ma, Wang, and Zeng, 2015; Wen and Zhou, 2020). For technology $n$, fixed costs in terms of labor used are $f(n)$ and marginal cost in terms of labor used is $\beta(n)$. We assume that $f$ and $\beta$ are twice continuously differentiable functions. To capture the substitution between fixed and marginal costs of production, we assume that a more advanced technology has a higher fixed but a lower marginal cost of production. Specifically, for $\gamma$ and $\theta$ denoting constants belonging to $R_{+}^{1}$, the fixed and marginal costs are

$$
\begin{aligned}
& f(n)=n^{\gamma}, \\
& \beta(n)=n^{-\theta} .
\end{aligned}
$$

From equation ( $1 \mathrm{a})$, when $\gamma$ increases, fixed costs increase. From equation (1b), when $\theta$ increases, marginal cost decreases.

The wage rate in region 1 is $w_{1}$. An intermediate good producer's output is $x_{1}$, and its profit is $p_{1} x_{1}-\left(f_{1}+\beta_{1} x_{1}\right) w_{1}$. Firms producing the same intermediate good engage in Cournot competition. The number of identical intermediate good producers in region 1 producing

\footnotetext{
${ }^{5}$ One purpose of having a continuum of intermediate goods instead of one intermediate good is to eliminate an intermediate good producer's market power in the labor market (Neary, 2016). Otherwise, it can be viewed that there is only one intermediate good.
} 
intermediate good $\omega$ is $m_{1}(\omega)$. An intermediate good producer takes the wage rate as given and chooses its technology and output to maximize its profit. The first order condition for an intermediate good producer's optimal choice of technology is ${ }^{6}$

$$
-f^{\prime}\left(n_{1}\right)-\beta^{\prime}\left(n_{1}\right) x_{1}=0 .
$$

From equation (2), it can be shown that an intermediate good producer chooses a more advanced technology when its level of output increases. The intuition is as follows: an increase in output increases the marginal benefit $-\beta^{\prime}\left(n_{1}\right) x_{1}$ from adopting a more advanced technology while the marginal cost $-f^{\prime}\left(n_{1}\right)$ does not change.

The first order condition for an intermediate good producer's optimal output choice requires that

$$
p_{1}\left(1+\frac{x_{1}}{p_{1}} \frac{\partial p_{1}}{\partial x_{1}}\right)=\beta_{1} w_{1} .
$$

Like Zhou (2007), the elasticity of demand faced by an intermediate good producer is $\frac{p_{1} \partial x_{1}}{x_{1} \partial p_{1}}=-m_{1} \delta$. Plugging this elasticity into equation (3) yields

$$
p_{1}=\frac{m_{1} \delta}{m_{1} \delta-1} \beta_{1} w_{1} .
$$

Firms enter the intermediate goods sector until the level of profit is zero. ${ }^{7}$ Zero profit for an intermediate good producer requires that

$$
p_{1} x_{1}-\left(f_{1}+\beta_{1} x_{1}\right) w_{1}=0 .
$$

\subsection{Market clearing conditions}

For the labor market in region 1 , each intermediate good producer demands $f_{1}+\beta_{1} x_{1}$ units of labor. Integrating over intermediate goods, total labor demand is $\int_{0}^{1} m_{1}\left(f_{1}+\beta_{1} x_{1}\right) d \omega$. Total labor supply is $L_{1}$. The clearance of the labor market in region 1 requires that

$$
\int_{0}^{1} m_{1}\left(f_{1}+\beta_{1} x_{1}\right) d \omega=L_{1} .
$$

For the market for the manufactured good in region 1 , since a consumer spends 1- $\alpha$ percent of income on the manufactured good and total income in region 1 is $T_{1}+w_{1} L_{1}$, total demand for the manufactured good is $(1-\alpha)\left(T_{1}+w_{1} L_{1}\right)$. The total value of the supply of the manufactured

\footnotetext{
${ }^{6}$ With the specifications of technologies in equations (1a) and (1b), it can be checked that the second order condition for a firm's optimal choice of technology is always satisfied.

${ }^{7}$ For an example that firms engage in Cournot competition with zero profits, see Chen and Shieh (2011).
} 
good equals the value of intermediate goods $\int_{0}^{1} p_{1} m_{1} x_{1} d \omega$. The clearance of the market for the manufactured good in region 1 requires that

$$
(1-\alpha)\left(T_{1}+w_{1} L_{1}\right)=p_{1} m_{1} x_{1}
$$

For the market for the agricultural good in region 1 , since a consumer spends $\alpha$ percent of income on the agricultural good and total income in region 1 is $T_{1}+w_{1} L_{1}$, total demand for the agricultural good is $\alpha\left(T_{1}+w_{1} L_{1}\right)$. The value of the total supply of the agricultural good is $T_{1}$. The clearance of the market for the agricultural good in region 1 requires that

$$
\alpha\left(T_{1}+w_{1} L_{1}\right)=T_{1} .
$$

\subsection{The autarky equilibrium}

In this model, we focus on a symmetric equilibrium in which the number of producing firms, the level of output, and the price are the same for all intermediate goods. In a symmetric equilibrium, the price of the manufactured good equals the price of an intermediate good: $P=p_{1}$. Also, the level of output of the manufactured good equals total output of an intermediate good. Equations (2) and (4)-(8) form a set of six equations defining six variables $n_{1}, m_{1}, w_{1}, x_{1}, p_{1}$, and $p^{A}$ as functions of exogenous parameters. ${ }^{8}$ Since all intermediate goods are symmetric and the total measure of intermediate goods is one, for simplicity we drop the integration operator for intermediate goods in a symmetric equilibrium. An autarky equilibrium is a tuple $\left(n_{1}, m_{1}, w_{1}, x_{1}\right.$, $p_{1}, p^{A}$ ) satisfying equations (2) and (4)-(8).

Interestingly, we can solve this set of equations explicitly. The following proposition establishes equilibrium values of variables when regions are in autarky.

Proposition 1: In autarky, the equilibrium values of variables are given by

$$
\begin{aligned}
& w_{1}=\frac{(1-\alpha) T_{1}}{\alpha L_{1}}, \\
& m_{1}=\frac{\theta+\gamma}{\delta \theta}, \\
& n_{1}=\left[\frac{\delta \theta^{2} L_{1}}{(\theta+\gamma)^{2}}\right]^{\frac{1}{\gamma}},
\end{aligned}
$$

\footnotetext{
${ }^{8}$ When equations (2) and (4)-(7) are satisfied, equation (8) is automatically satisfied. With Walras's law in mind, this redundancy of equation (8) is not surprising.
} 


$$
\begin{aligned}
& x_{1}=\frac{\gamma}{\theta}\left[\frac{\delta \theta^{2} L_{1}}{(\theta+\gamma)^{2}}\right]^{\frac{\gamma+\theta}{\gamma}}, \\
& p_{1}=\frac{(1-\alpha)(\theta+\gamma)^{\frac{\gamma+2 \theta}{\gamma}}}{\alpha \gamma \delta^{\frac{\gamma}{\theta}} \theta^{\frac{2 \theta}{\gamma}} L_{1}^{\frac{\gamma+\theta}{\gamma}}} T_{1} .
\end{aligned}
$$

From equation (11), an intermediate good producer's equilibrium technology increases with population size. This result can be interpreted as the division of labor (the level of technology) increases with the size of the market (Zhou, 2004). Results in Proposition 1 are intuitive. With increasing returns in the intermediate good sector, from equation (12), an intermediate good producer's output increases with the size of the population. With a higher level of output, an intermediate good producer chooses a more advanced technology because the higher fixed cost can be spread over a higher level of output and the average cost of production decreases. With a lower average cost, the price of an intermediate good decreases with population size because the price equals the average cost when firms earn a profit of zero. Those results are consistent with empirical evidence discussed in the Introduction. From equations (10)-(13), when the absolute value of the elasticity of substitution among intermediate goods increases, an intermediate good producer produces more, and the number of intermediate good producers decreases. As intermediate good producers choose more advanced technologies, the price of an intermediate good decreases with the absolute value of the elasticity of substitution among intermediate goods.

\section{Worker movement without trade}

If the two regions have equal numbers of workers and farmers, since the prices of the agricultural good and the manufactured good will be the same between the two regions, there is no regional trade. The equilibrium with equal distribution of workers between the two regions is stable if a worker's utility decreases with the number of workers in this region. The following proposition addresses the stability of this equilibrium.

Proposition 2: The equilibrium with equal distribution of workers between the two regions is stable if and only if $\theta-\gamma \alpha-\alpha \theta<0$. 
The percentage of income spent on the agricultural good is one of the three key parameters in Krugman (1991). Proposition 2 shows that the equilibrium with equal distribution of workers between the two regions is stable if the percentage of income spent on the agricultural good is sufficiently high. Compared with Zhou (2007), this condition for stability is simpler. In Zhou (2007, p. 926), the ratio between population size and the fixed cost of production is part of the stability condition. With the endogenous choice of technology in this model, the fixed cost is a function of population size. Overall, impact of the fixed cost and population size cancel out and both are absent from the stability condition, while parameters measuring technologies enter this stability condition.

\section{Regional trade}

We now allow trade between regions. There is no transportation cost for the agricultural good. Thus, the opening of trade will lead to equal price of the agricultural good in the two regions. Transportation costs for the manufactured good are of the iceberg type commonly used in the literature. Specifically, for $1+t$ units of the manufactured good sent out, only one unit will arrive,

where $t \in R_{+}^{1}$. We assume that market for the manufactured good in the two regions are integrated. Different from Krugman (1991) and Zhou (2007), the numbers of farmers in the two regions in this paper are not required to be equal.

Total number of workers in the two regions is exogenously given:

$$
L_{1}+L_{2}=L
$$

Without loss of generality, we assume that the number of workers in the manufacturing sector in region 1 is larger than that in region 2: $L_{1}>L_{2}$. We also assume that the number of farmers in region 1 is not larger than that in region 2: $T_{1} \leq T_{2}$. From equation (13), the price of the manufactured good in region 1 before the opening of regional trade will be smaller than that in region 2 . With the opening of regional trade, the trade pattern is interindustry trade rather than intraindustry trade: region 1 exports the manufactured good to region 2 and imports the agricultural good from region 2.

If there is regional trade, from the specification of the iceberg transportation technology, the relationship between the prices of the manufactured good in the two regions is

$$
p_{2}=(1+t) p_{1} \text {. }
$$


Like equation (2), the optimal choice of technology for an intermediate good producer in region 2 requires that

$$
-f^{\prime}\left(n_{2}\right)-\beta^{\prime}\left(n_{2}\right) x_{2}=0
$$

Like equation (5), zero profit for an intermediate good producer in region 2 requires that

$$
p_{2} x_{2}-\left(f_{2}+\beta_{2} x_{2}\right) w_{2}=0 \text {. }
$$

Like equation (6), the clearance of the labor market for workers in region 2 requires that

$$
\int_{0}^{1} m_{2}\left(f_{2}+\beta_{2} x_{2}\right) d \omega=L_{2} .
$$

For the market for the agricultural good, total demand for the agricultural good from the two regions is $\alpha\left(T_{1}+T_{2}+w_{1} L_{1}+w_{2} L_{2}\right)$. Total value of the supply of the agricultural good from the two regions is $T_{1}+T_{2}$. The clearance of the market for the agricultural good requires that

$$
\alpha\left(T_{1}+T_{2}+w_{1} L_{1}+w_{2} L_{2}\right)=T_{1}+T_{2} .
$$

For the market for the manufactured good in region 1, the amount of exports of the manufactured good from region 1 to region 2 is $E$. Total demand for the manufactured good in region 1 is $(1-\alpha)\left(T_{1}+w_{1} L_{1}\right)$ and total value of the supply of the manufactured good is $p_{1}\left(m_{1} x_{1}-E\right)$. The clearance of the market for the manufactured good in region 1 requires that

$$
(1-\alpha)\left(T_{1}+w_{1} L_{1}\right)=p_{1}\left(m_{1} x_{1}-E\right) .
$$

For the market for the manufactured good in region 2, the amount of arrived imports of the manufactured good in region 2 is $I$. Total demand for the manufactured good in region 2 is (1$\alpha)\left(T_{2}+w_{2} L_{2}\right)$ and the total value of the supply of the manufactured good is $p_{2}\left(m_{2} x_{2}+I\right)$. The clearance of the market for the manufactured good in region 2 requires that

$$
(1-\alpha)\left(T_{2}+w_{2} L_{2}\right)=p_{2}\left(m_{2} x_{2}+I\right) .
$$

With the specification of iceberg transportation cost of the manufactured good, $E=(1+$ $t) I$. Combining this result with equations (17) and (18) yields

$$
(1-\alpha)\left(T_{1}+T_{2}+w_{1} L_{1}+w_{2} L_{2}\right)=p_{1}\left[m_{1} x_{1}+(1+t) m_{2} x_{2}\right] .
$$

For $i=1,2$, a region $i$ intermediate good producer's optimal choice of output yields $x_{i}+$ $p_{i} \frac{\partial x_{i}}{\partial p_{i}}-\beta_{i} w_{i}=0$. Like the equilibrium under autarky, it can be shown that $\frac{\partial x_{1}}{\partial p_{1}}=$ $-\frac{\delta\left[m_{1} x_{1}+(1+t) m_{2} x_{2}\right]}{p_{1}}$ and $\frac{\partial x_{2}}{\partial p_{2}}=-\frac{\delta\left[m_{1} x_{1}+(1+t) m_{2} x_{2}\right]}{(1+t) p_{2}}$. Plugging those results into $x_{i}+p_{i} \frac{\partial x_{i}}{\partial p_{i}}-$ $\beta_{i} w_{i}=0$ yields

$$
p_{1}\left(1-\frac{x_{1}}{\delta\left[m_{1} x_{1}+(1+t) m_{2} x_{2}\right]}\right)=\beta_{1} w_{1}
$$




$$
p_{2}\left(1-\frac{(1+t) x_{2}}{\delta\left[m_{1} x_{1}+(1+t) m_{2} x_{2}\right]}\right)=\beta_{2} w_{2} .
$$

With regional trade, equations (2) and (5)-(6) are still valid. Those equations and equations $\left(2^{*}\right),\left(5^{*}\right),\left(6^{*}\right),(15),(19),(20)$, and $\left(20^{*}\right)$ form a system of 11 equations defining a set of 11 variables $n_{1}, n_{2}, m_{1}, m_{2}, w_{1}, w_{2}, x_{1}, x_{2}, p_{1}, p_{2}$, and $p^{A}$ as functions of exogenous parameters. An equilibrium with regional trade is a tuple $\left(n_{1}, n_{2}, m_{1}, m_{2}, w_{1}, w_{2}, x_{1}, x_{2}, p_{1}, p_{2}, p^{A}\right)$ satisfying equations (2), (2*), (5)-(6), (5*)-(6*), (15), (19), (20), and (20*). Interestingly, while there are 11 equations, we can still solve them explicitly. The results are stated in the following proposition.

Proposition 3: For the equilibrium with regional trade, the equilibrium values of variables are

$$
\begin{aligned}
& p_{1}=\frac{(1-\alpha)\left(T_{1}+T_{2}\right)(\theta+\gamma)^{\frac{2 \theta+\gamma}{\gamma}}}{\alpha \gamma \delta^{\frac{\theta}{\gamma}} \frac{2 \theta}{\gamma}\left[L_{1}+(1+t)^{\frac{\gamma}{\gamma+\theta}} L_{2}\right]^{\frac{\gamma+\theta}{\gamma}}} . \\
& w_{1}=\frac{(1-\alpha)\left(T_{1}+T_{2}\right)}{\alpha\left[L_{1}+(1+t)^{\frac{\gamma}{\gamma+\theta}} L_{2}\right]} \text {, } \\
& w_{2}=\frac{(1-\alpha)\left(T_{1}+T_{2}\right)}{\alpha\left[L_{1}+(1+t)^{\frac{\gamma}{\gamma+\theta}} L_{2}\right]}(1+t)^{\frac{\gamma}{\gamma+\theta}} \text {, } \\
& n_{1}=\delta^{\frac{1}{\gamma}}\left(\frac{\theta}{\theta+\gamma}\right)^{\frac{2}{\gamma}}\left[L_{1}+(1+t)^{\frac{\gamma}{\gamma+\theta}} L_{2}\right]^{\frac{1}{\gamma}} \text {, } \\
& n_{2}=\delta^{\frac{1}{\gamma}}\left(\frac{\theta}{\theta+\gamma}\right)^{\frac{2}{\gamma}}\left[L_{1}+(1+t)^{\frac{\gamma}{\gamma+\theta}} L_{2}\right]^{\frac{1}{\gamma}} /(1+t)^{\frac{1}{\gamma+\theta}} \\
& x_{1}=\gamma \frac{\delta^{\frac{\theta+\gamma}{\gamma}} \theta^{\frac{2 \theta+\gamma}{\gamma}}}{(\theta+\gamma)^{\frac{2 \theta+2 \gamma}{\gamma}}}\left[L_{1}+(1+t)^{\frac{\gamma}{\gamma+\theta}} L_{2}\right]^{\frac{\gamma+\theta}{\gamma}} \text {, } \\
& x_{2}=\gamma \frac{\delta^{\frac{\theta+\gamma}{\gamma}} \theta^{\frac{2 \theta+\gamma}{\gamma}}}{(1+t)(\theta+\gamma)^{\frac{2 \theta+2 \gamma}{\gamma}}}\left[L_{1}+(1+t)^{\frac{\gamma}{\gamma+\theta}} L_{2}\right]^{\frac{\gamma+\theta}{\gamma}} \\
& m_{1}=\frac{(\theta+\gamma) L_{1}}{\theta \delta\left[L_{1}+(1+t)^{\frac{\gamma}{\gamma+\theta}} L_{2}\right]}
\end{aligned}
$$




$$
m_{2}=\frac{(\theta+\gamma)(1+t)^{\frac{\gamma}{\gamma+\theta}} L_{2}}{\theta \delta\left[L_{1}+(1+t)^{\frac{\gamma}{\gamma+\theta}} L_{2}\right]}
$$

Consistent with empirical evidence, from equations (24) and (25), intermediate good producers in region 1 with a higher number of workers choose more advanced technologies and have lower marginal costs of production than those in region 2 with a lower number of workers. From equations (26) and (27), the level of output for an intermediate good producer in region 1 is higher than that in region 2. From equations (28) and (29), the number of intermediate good producers in a region increases with the number of workers in this region and decreases with the number of workers in the other region.

An inspection of Propositions 1 and 3 reveals the following. First, when the number of workers and the number of farmers in region 2 becomes zero, the results in Proposition 3 degenerate to those in Proposition 1. For example, if $L_{2}=0$ and $T_{2}=0$, equation (25) degenerates to equation (13). That is, the autarky equilibrium can be viewed as a special case of regional trade with the numbers of workers and farmers are zero in region 2. Second, when the level of transportation cost is zero, equilibrium values of variables in Proposition 3 will be the same as those in Proposition 1 with the number of farmers of region 1 replaced by the sum of the numbers of farmers and the number of workers in region 1 replaced by the sum of the number of workers in the two regions. That is, the distribution of workers and farmers between the two regions will not affect technology choice in an equilibrium with regional trade if there is no transportation cost. Third, from equations (10), (28), and (29), the sum of firms producing an intermediate input in the two regions in the trade equilibrium is equal to the number of firms producing an intermediate input in the autarky equilibrium. Finally, starting from autarky, both regions will choose more advanced technologies with the opening of regional trade.

\section{Worker movement with regional trade}

In the equilibrium with regional trade, from equations (25)-(27), a region 2 worker's consumption of the agricultural good is higher while his consumption of the manufactured good is lower than that of a region 1 worker. If the percentage of income spent on the agricultural good is sufficiently low, the level of utility for a region 2 worker will be lower than that of a region 1 worker. Then a worker in region 2 has an incentive to move to region 1. 
Naturally a worker's choice of location is a very interesting issue, we do not study explicitly address this issue here. This can be justified on the ground that in some situations workers may not have this choice such as when Hukou system (household registration system) was practiced in China. Under this system, if an individual moves without permission, this individual may not have access to various kinds of benefits such as child care. Also, it can be argued that some factors not included in this model may prevent a worker from moving, such as an individual's preference to stay at hometown. What is the impact on endogenous variables if a worker moves from region 2 to region 1 ? The following proposition addresses the impact on technology choices by intermediate good producers.

Proposition 4: When a worker moves from region 2 to region 1, intermediate producers in both regions choose less advanced technologies.

Proposition 4 is surprising because we may have expected that intermediate good producers in region 1 choose more advanced technologies when there are more workers in this region. This result is less surprising when we interpret worker movement as relocation of workers between regions, rather than an overall increase in the number of workers. To understand Proposition 4, from equation (2), a firm's equilibrium level of technology increases with its equilibrium level of output, which is endogenously determined by population size (a measure of market size). If we compare equation (24) with (11), technology choice in the equilibrium with regional trade is like that in the autarky equilibrium by replacing population size $L_{1}$ with the weighted population of the two regions $L_{1}+(1+t)^{\frac{\gamma}{\gamma+\theta}} L_{2}$ because markets for the manufactured good is assumed to be integrated. When calculating weighted population, population in region 2 is augmented by $(1+$ $t)^{\frac{\gamma}{\gamma+\theta}}$ because of the existence of transportation costs. Since $L_{1}+(1+t)^{\frac{\gamma}{\gamma+\theta}} L_{2}$ is larger than $L_{1}$, intermediate good producers choose more advanced technologies in the equilibrium with regional trade. When a worker moves from region 2 to region 1, weighted population of the two regions $L_{1}+(1+t)^{\frac{\gamma}{\gamma+\theta}} L_{2}$ becomes lower. With a lower market size, from equations (26) and (27), outputs of intermediate good producers are lower, thus intermediate good producers in both regions choose less advanced technologies. 
Alternatively, when a worker moves from region 2 to region 1, "total effective output" of the manufactured good defined as the sum of regional outputs weighted by transportation costs decreases. The reasoning is as follows. For a worker in region 2, the level of demand for the manufactured good is $\frac{(1-\alpha) w_{2}}{p_{2}}$. Taking account of transportation costs, effective demand for a region 2 worker is $\frac{(1+t)(1-\alpha) w_{2}}{p_{2}}$. A region 1 worker's demand for the manufactured good is $\frac{(1-\alpha) w_{1}}{p_{1}}$, which is lower than $\frac{(1+t)(1-\alpha) w_{2}}{p_{2}}$. That is, total effective output $m_{1} x_{1}+(1+t) m_{2} x_{2}$ decreases when a worker moves from region 2 to region 1 . Because intermediate good producers choose less advanced technologies when output decreases, intermediate good producers in both regions choose less advanced technologies when a worker moves to region 1. For a given number of manufacturing workers $L$, technologies in both regions are most advanced when the difference in the number of workers between the two regions is just enough for regional trade to be possible (from equations (24) and (25)). Those technologies are more advanced than the one when all workers are concentrated in one region. ${ }^{9}$

Will the choice of technology work as a channel for the concentration of industries? By using Proposition 3 and equation (14) (which shows that the sum of workers in the two regions is a constant), we can get the following results when $L_{1}$ increases and $L_{2}$ decreases simultaneously. First, from equation (21), the price of the manufactured good in region 1 increases with the number of workers in region 1 . The intuition behind this result is that the average cost of producing intermediate goods increases when firms choose less advanced technologies. Second, from equations (22) and (23), the wage rates increase with the number of workers in region 1. This wage increase can be understood from equation (16) which shows that $w_{1} L_{1}+w_{2} L_{2}$ is a constant because of the assumption of homothetic preferences. When $L_{2}$ decreases and $L_{1}$ increases by the same amount, because $w_{1}<w_{2}, w_{1} L_{1}+w_{2} L_{2}$ would decrease if $w_{1}$ and $w_{2}$ do not change. That is, $w_{1}$ and $w_{2}$ increase to ensure that $w_{1} L_{1}+w_{2} L_{2}$ does not change. Interestingly, the wage ratio between the two regions is a constant and is affected by the level of transportation cost. When more workers move to region 1 , the wage ratio will not change. This constant wage ratio is surprising because with a higher number of workers in region 1 and increasing returns in the manufacturing sector, we may have expected that the wage rate in region 1 will increase relatively

\footnotetext{
9 This result can be established by comparing technologies in equations (24) and (25) with those under zero transportation costs and that workers concentrate in region 1.
} 
and that the wage ratio between the two regions will widen. To understand this result that the wage ratio is constant, the number of intermediate good producers in region 2 decreases when workers move out from region 2. Thus, when workers move from region 2 to region 1, intermediate good producers in both regions adjust their technologies. In equilibrium, the ratio of technologies in the two regions is a constant not affected by the distribution of workers between the two regions. Technology determines the marginal units of labor to produce one unit of intermediate good and thus labor productivity. Since the technology ratio does not change, the wage ratio does not change.

The following proposition studies whether the equilibrium that all workers are concentrated in one region is stable.

Proposition 5: The equilibrium that all workers are concentrated in region 1 is stable if and only if

$$
n_{2}<\frac{\alpha^{\frac{1}{\theta}} \frac{\theta+\gamma}{\frac{\gamma}{\gamma}} \delta \frac{1}{\gamma} \frac{2}{\gamma}^{\frac{\alpha}{\gamma}}}{(1+t)^{\frac{\alpha}{\theta}}(\theta+\gamma)^{\frac{2}{\gamma}}}
$$

where $n_{2}$ is defined implicitly by

$$
\frac{(1+t)\left(T_{1}+T_{2}\right)(\theta+\gamma)^{\frac{2 \theta+\gamma}{\gamma}}}{\delta^{\frac{\theta}{\gamma}} \frac{2 \theta}{\gamma}{ }_{L}^{\frac{\gamma+\theta}{\gamma}}} n_{2}^{\gamma+\theta}-(\gamma+\theta)(1-\alpha)(1+t)^{1-\alpha} \frac{\left(T_{1}+T_{2}\right)}{L} n_{2} \gamma-\theta \alpha T_{2}=0
$$

Once we have the parameter values, we can solve equation (31) to get the value of $n_{2}$ and then check whether (30) is satisfied. The left-hand side of equation (31) is an increasing function of $n_{2}$. Without solving (31), we can derive the following result. From equation (31), when $T_{2}$ increases, $n_{2}$ increases. Thus, when the number of farmers in region 2 increases or that in region 1 decreases, the equilibrium with all workers concentrated in region 1 is less likely to be stable.

\section{Conclusion}

Empirical research has shown that firms located in areas with larger populations are on average larger and more productive. In this paper, we have shown that allowing firms to choose their technologies helps explaining this empirical observation. This incorporation of technology choice into a general equilibrium model of economic geography is tractable. We have established the following results analytically. First, regardless of the existence of regional trade or not, an intermediate good producer in the region with a higher number of workers produces a higher level 
of output and has a lower marginal cost of production. If a worker moves from the region with a lower number of workers to the region with a higher number of workers, interestingly intermediate good producers in both regions choose less advanced technologies. Second, with regional trade, the wage ratio between the two regions is a constant and is affected by the level of transportation costs. Finally, the equilibrium that all workers concentrate in region 1 is less likely to be stable when the endowment of farmers in region 2 is relatively large.

There are some potential generalizations and extensions of the model. First, in this model we have used special functional forms in specifying fixed and marginal costs. It will be interesting to study more general cost functions. While this kind of extension may be less tractable, we believe that the main result that firms in a region with a higher number of workers will have a higher level of output and choose more advanced technologies will be robust because our main result is based on the tradeoff between marginal and fixed costs rather than on specific functional forms. Second, the model can be extended to address the dynamics of worker mobility by specifying worker mobility as a function of utility difference between the two regions. Third, as suggested by an anonymous reviewer, the model can be generalized to incorporate capital as an additional factor of production. When a worker moves from region 2 to region 1, this changes the supply of labor and affects the relative price of capital to labor and thus an intermediate firm's technology choice. Finally, in this model, intermediate good producers have market power in the goods market. It will be interesting to study government policies such as tax policies trying to address distortions from the existence of market power.

\section{Acknowledgements}

I thank Sunghyun Henry Kim, Hyeogug Kwon, Lei Wen, and an anonymous reviewer for their valuable suggestions. The usual disclaimer applies.

\section{Appendix}

\section{Proof of Proposition 1:}

First, equation (9) comes from equation (8). Second, from equations (1a), (1b), and (2),

$f_{1}+\beta_{1} x_{1}=\frac{\theta+\gamma}{\theta} n_{1}^{\gamma}$. Plugging $f_{1}+\beta_{1} x_{1}=\frac{\theta+\gamma}{\theta} n_{1}^{\gamma}$ into equation (5) yields $w_{1}=\frac{\gamma}{\theta+\gamma} p_{1} n_{1}{ }^{\theta}$. Plugging $f_{1}+\beta_{1} x_{1}=\frac{\theta+\gamma}{\theta} n_{1}^{\gamma}$ into equation (6) yields $m_{1}=\frac{\theta L_{1}}{\theta+\gamma} n_{1}^{-\gamma}$. Plugging $w_{1}=\frac{\gamma}{\theta+\gamma} p_{1} n_{1}{ }^{\theta}$ 
and $m_{1}=\frac{\theta L_{1}}{\theta+\gamma} n_{1}{ }^{-\gamma}$ into equation (4) yields (11). Combining equation (11) and $m_{1}=\frac{\theta L_{1}}{\theta+\gamma} n_{1}{ }^{-\gamma}$ yields equation (10), and combining equations (2) and (11) yields (12). Plugging the value of $w_{1}$ from equation (9), the value of $m_{1}$ from equation (10), and the value of $x_{1}$ from equation (12) into (7) yields (13).

\section{Proof of Proposition 2:}

From the specification of the utility function and equations (9) and (13), a worker's utility is

$$
U=\frac{w}{\left(p_{1}\right)^{1-\alpha}}=\frac{\left[(1-\alpha) T_{1}\right]^{\alpha}}{\alpha^{\alpha}}\left[\frac{\gamma \delta^{\frac{\gamma}{\delta} \theta^{\frac{2 \theta}{\gamma}}}}{(\theta+\gamma)^{\frac{\gamma+2 \theta}{\gamma}}}\right]^{1-\alpha} \quad L_{1}^{\frac{(\gamma+\theta)(1-\alpha)}{\gamma}-1}
$$

Differentiation of the above equation yields

$$
\frac{d U}{d L_{1}}=\left(\frac{(\gamma+\theta)(1-\alpha)}{\gamma}-1\right) \frac{\left[(1-\alpha) T_{1}\right]^{\alpha}}{\alpha^{\alpha}}\left[\frac{\gamma \delta \delta^{\frac{\gamma}{} \theta^{\frac{2 \theta}{\gamma}}}}{(\theta+\gamma)^{\frac{\gamma+2 \theta}{\gamma}}}\right]^{1-\alpha} L_{1}^{\frac{(\gamma+\theta)(1-\alpha)}{\gamma}-2}
$$

Thus $\frac{d U}{d L_{1}}<0$ if and only if $\theta-\gamma \alpha-\alpha \theta<0$.

Proof of Proposition 3:

From equation (5), the level of output for an intermediate good producer in region 1 is

$$
x_{1}=\frac{f_{1} w_{1}}{p_{1}-\beta_{1} w_{1}} \text {. }
$$

Combining equations (16) and (19) yields

$$
m_{1} x_{1}+(1+t) m_{2} x_{2}=\frac{(1-\alpha)}{\alpha p_{1}}\left(T_{1}+T_{2}\right) .
$$

Plugging (A1) and (A2) into equation (20) yields

$$
\left(\frac{p_{1}}{p_{1}-\beta_{1} w_{1}}\right)^{2} \alpha f_{1} w_{1}-(1-\alpha)\left(T_{1}+T_{2}\right)=0 .
$$

Combining equations (1a), (1b), (2) with (A1) yields $n_{1}=\left[\frac{(\theta+\gamma) w_{1}}{\gamma p_{1}}\right]^{\frac{1}{\theta}}$. Plugging this result into (A3) yields

$$
w_{1}=\left[\frac{\delta(1-\alpha)\left(T_{1}+T_{2}\right) \theta^{2} \gamma^{\frac{\gamma}{\theta}}}{\alpha(\theta+\gamma)^{2+\frac{\gamma}{\theta}}} p_{1}^{\frac{\gamma}{\theta}}\right]^{\frac{\theta}{\gamma+\theta}} .
$$

From equation $\left(5^{*}\right)$, the level of output for an intermediate good producer in region 2 is 


$$
x_{2}=\frac{f_{2} w_{2}}{p_{2}-\beta_{2} w_{2}}
$$

Plugging (A2) and (A5) into (20*) yields

$$
\left(\frac{(1+t) p_{1}}{(1+t) p_{1}-\beta_{2} w_{2}}\right)^{2} \alpha f_{2} w_{2}-\delta(1-\alpha)\left(T_{1}+T_{2}\right)=0
$$

Combining equation (1a), (1b), $\left(2^{*}\right)$, and (A5) yields $n_{2}=\left[\frac{(\theta+\gamma) w_{2}}{\gamma(1+t) p_{1}}\right]^{\frac{1}{\theta}}$. Plugging this result into (A6) yields

$$
w_{2}=\left[\frac{\delta(1-\alpha)\left(T_{1}+T_{2}\right) \theta^{2} \gamma^{\frac{\gamma}{\theta}}(1+t)^{\frac{\gamma}{\theta}}}{\alpha(\theta+\gamma)^{2+\frac{\gamma}{\theta}}} p_{1}^{\frac{\gamma}{\theta}}\right]^{\frac{\theta}{\gamma+\theta}} .
$$

Equilibrium values of variables are derived as follows. First, plugging the value of $w_{1}$ from equation (A4) and the value of $w_{2}$ from equation (A7) into (16) yields (21). Second, plugging the value of $p_{1}$ from equation (21) into (A4) yields (22). Similarly, plugging the value of $p_{1}$ from equation (21) into (A7) yields (23). Third, plugging the value of $p_{1}$ from equation (21) and the value of $w_{1}$ from equation (22) into $n_{1}=\left[\frac{(\theta+\gamma) w_{1}}{\gamma p_{1}}\right]^{\frac{1}{\theta}}$ yields (24). Similarly, plugging the value of $p_{1}$ from equation (21) and the value of $w_{2}$ from equation (23) into $n_{2}=\left[\frac{(\theta+\gamma) w_{2}}{\gamma(1+t) p_{1}}\right]^{\frac{1}{\theta}}$ yields (25). Fourth, plugging the value of $n_{1}$ from equation (24), the value of $w_{1}$ from equation (22), and the value of $p_{1}$ from equation (21) into (A1) yields (26). Similarly, plugging the value of $n_{2}$ from equation (25), the value of $w_{2}$ from equation (23), and the value of $p_{1}$ from equation (21) into (A5) yields (27). Finally, plugging the value of $n_{1}$ from equation (24) and the value of $x_{1}$ from equation (26) into (6) yields (28). Similarly, plugging the value of $n_{2}$ from equation (25) and the value of $x_{2}$ from equation (27) into $\left(6^{*}\right)$ yields (29).

\section{Proof of Proposition 4:}

Plugging $L_{2}=L-L_{1}$ into equations (24) and (25) yields

$$
\begin{aligned}
& n_{1}=\delta^{\frac{1}{\gamma}}\left(\frac{\theta}{\theta+\gamma}\right)^{\frac{2}{\gamma}}\left[\left(1-(1+t)^{\frac{\gamma}{\gamma+\theta}}\right) L_{1}+(1+t)^{\frac{\gamma}{\gamma+\theta}} L\right]^{\frac{1}{\gamma}} \\
& n_{2}=\delta^{\frac{1}{\gamma}}\left(\frac{\theta}{\theta+\gamma}\right)^{\frac{2}{\gamma}}\left[\left(1-(1+t)^{\frac{\gamma}{\gamma+\theta}}\right) L_{1}+(1+t)^{\frac{\gamma}{\gamma+\theta}} L\right]^{\frac{1}{\gamma}} /(1+t)^{\frac{1}{\gamma+\theta}}
\end{aligned}
$$


Since $1-(1+t)^{\frac{\gamma}{\gamma+\theta}}<0$, differentiation of the above two equations yields that $\frac{d n_{1}}{d L_{1}}<0$ and $\frac{d n_{2}}{d L_{1}}<0$

\section{Proof of Proposition 5:}

When all workers are concentrated in region 1, the following equilibrium conditions are valid:

$$
\begin{aligned}
& f^{\prime}\left(n_{1}\right)+\beta^{\prime}\left(n_{1}\right) x_{1}=0, \\
& p_{1} x_{1}-\left(f_{1}+\beta_{1} x_{1}\right) w_{1}=0, \\
& \alpha w_{1} L-(1-\alpha)\left(T_{1}+T_{2}\right)=0, \\
& \left(\frac{p_{1}}{p_{1}-\beta_{1} w_{1}}\right)^{2} \alpha f_{1} w_{1}-\delta(1-\alpha)\left(T_{1}+T_{2}\right)=0 .
\end{aligned}
$$

Equation (A8) is the condition for the clearance of the market for the agricultural good in region 1. Equation (A9) comes from an intermediate good producer's optimal choice of output. Solving the set of equations (2), (5), (A8), and (A9) yields

$$
\begin{aligned}
& w_{1}=\frac{(1-\alpha)\left(T_{1}+T_{2}\right)}{\alpha L}, \\
& p_{1}=\frac{(1-\alpha)\left(T_{1}+T_{2}\right)(\theta+\gamma)^{\frac{2 \theta+\gamma}{\gamma}}}{\alpha \gamma \frac{\theta}{\gamma} \theta^{\frac{2 \theta}{\gamma}} \frac{\gamma+\theta}{\gamma}} .
\end{aligned}
$$

For a worker moving to region 2 and maintaining the same level of utility as a worker in region 1 , from the specification of a consumer's utility function and equation (15), the lowest wage rate in region 2 should satisfy

$$
w_{2}=w_{1}(1+t)^{1-\alpha}
$$

For an intermediate good producer moving to region 2 , its profit is $(1+t) p_{1} x_{2}-\left(f_{2}+\right.$ $\left.\beta_{2} x_{2}\right) w_{2}$. For this firm to make a nonnegative profit, we need

$$
(1+t) p_{1} x_{2}-\left(f_{2}+\beta_{2} x_{2}\right) w_{2} \geq 0 .
$$

Total income in region 2 is the sum of income from farmers $T_{2}$ and workers in this region $\left(f_{2}+\beta_{2} x_{2}\right) w_{2}$. Thus, total income in region 2 is $T_{2}+\left(f_{2}+\beta_{2} x_{2}\right) w_{2}$. Since $1-\alpha$ percent of income is spent on the manufactured good, demand for the firm moving to region 2 is (1$\alpha)\left[T_{2}+\left(f_{2}+\beta_{2} x_{2}\right) w_{2}\right]$. This firm's revenue is $p_{2} x_{2}$. Thus, we have $(1-\alpha)\left[T_{2}+\left(f_{2}+\right.\right.$ $\left.\left.\beta_{2} x_{2}\right) w_{2}\right]=p_{2} x_{2}$. Rearrangement of this equation yields 


$$
x_{2}=\frac{(1-\alpha)\left(f_{2} w_{2}+T_{2}\right)}{(1+t) p_{1}-(1-\alpha) \beta_{2} w_{2}} .
$$

This intermediate good producer chooses its technology to maximize profit $(1+t) p_{1} x_{2}-$ $\left(f_{2}+\beta_{2} x_{2}\right) w_{2}$. The first order condition with respect to $n_{2}$ is $\left[(1+t) p_{1}-\beta_{2} w_{2}\right] \frac{\partial x_{2}}{\partial n_{2}}-\left(f_{2}{ }^{\prime}+\right.$ $\left.\beta_{2}{ }^{\prime} x_{2}\right) w_{2}=0$. It can be checked that $\left[(1+t) p_{1}-\beta_{2} w_{2}\right] \frac{\partial x_{2}}{\partial n_{2}}=0$. The intuition behind this is that the level of technology is optimally chosen for a given level of output. Thus, this intermediate good producer's optimal choice of technology degenerates to $-\left(f_{2}{ }^{\prime}+\beta_{2}{ }^{\prime} x_{2}\right) w_{2}=0$. Rearrangement of this equation yields

$$
x_{2}=-\frac{f_{2}^{\prime}}{\beta_{2}^{\prime}} .
$$

Equations (A14) and (A15) lead to

$$
-\frac{f_{2}^{\prime}}{\beta_{2}{ }^{\prime}}=\frac{(1-\alpha)\left(f_{2} w_{2}+T_{2}\right)}{(1+t) p_{1}-(1-\alpha) \beta_{2} w_{2}} .
$$

Using the specifications of fixed and marginal costs, the above equation yields equation (31) defining $n_{2}$.

For (A13) to be invalid, from equations (1a), (1b), (A12), and (A15), the following is needed:

$$
(1+t) \gamma p_{1} n_{2}^{\gamma+\theta}-(\gamma+\theta) w_{2} n_{2}^{\gamma}<0 .
$$

Plugging the value of $w_{1}$ from (A10) and $p_{1}$ from (A11) into (A16) yields

$$
n_{2}<\frac{\alpha^{\frac{1}{\theta}} L^{\frac{\theta+\gamma}{\gamma \theta}} \delta^{\frac{1}{\gamma}} \theta^{\frac{2}{\gamma}}}{(1+t)^{\frac{\alpha}{\theta}}(\theta+\gamma)^{\frac{2}{\gamma}}}
$$

\section{References}

Belleflamme, Paul, Pierre Picard, and Jacques-Francois Thisse. 2000. An economic theory of regional clusters. Journal of Urban Economics 48, 158-184.

Chandler, Alfred. 1990. Scale and Scope: The Dynamics of Industrial Capitalism. Cambridge, MA: Harvard University Press.

Chen, Ming Chieh, and Yeung-Nan Shieh. 2011. Specific commodity taxes, output and location decision under free entry oligopoly. Annals of Regional Science 47, 25-36.

Combes, Pierre-Philippe. 1997. Industrial agglomeration under Cournot competition. Annales d'Économie et de Statistique 45, 161-182. 
Combes, Pierre-Philippe, Gilles Duranton, Laurent Gobillon, Diego Puga, and Sebastien Roux. 2012. The productivity advantages of large cities: distinguishing agglomeration from firm selection. Econometrica 80, 2543-2594.

Combes, Pierre-Philippe, and Miren Lafourcade. 2011. Competition, market access and economic geography: Structural estimation and predictions for France. Regional Science and Urban Economics 41, 508-524.

Dewit, Gerda, Dermot Leahy, and Catia Montagna. 2013. Unemployment protection, flexibility and firms' strategic location decisions under uncertainty. Economica 80, 441-474.

Fujita, Masahisa, Paul Krugman, and Anthony Venables. 1999. The Spatial Economy: Cities, Regions, and International Trade. Boston, MA: MIT Press.

He, Huanlang, and Zhihao Yu. 2015. The evolving patterns of global production of multi-product firms. Canadian Journal of Economics 48, 1175-1194.

Holmes, Thomas, and John Stevens. 2002. Geographic concentration and establishment scale. Review of Economics and Statistics 84, 682-690.

Krugman, Paul. 1991. Increasing returns and economic Geography. Journal of Political Economy 99, 483-499.

Levinson, Marc. 2006. The Box: How the Shipping Container Made the World Smaller and the World Economy Bigger. Princeton, NJ: Princeton University Press.

Li, Dongya, Yi Lu, and Mingqin Wu. 2012. Industrial agglomeration and firm size: evidence from China. Regional Science and Urban Economics 42, 135-143.

Ma, Hongkun, X. Henry Wang, and Chenhang Zeng. 2015. Cournot and Bertrand competition in a differentiated duopoly with endogenous technology adoption. Annals of Economics and Finance 16, 231-253.

Neary, J. Peter. 2001. Of hype and hyperbolas: introducing the new economic geography. Journal of Economic Literature 39, 536-561.

Neary, J. Peter. 2016. International trade in general oligopolistic equilibrium. Review of International Economics 24, 669-698.

Nocco, Antonella. 2005. The rise and fall of regional inequalities with technological differences and knowledge spillovers. Regional Science and Urban Economics 35, 542-569.

Oi, Walter, and Todd Idson. 1999. Firm size and wages. In Orley Ashenfelter and David Card (Eds.), Handbook of Labor Economics, vol. 3B. Amsterdam: Elsevier, pp. 2165-2214. 
Porter, Michael. 1990. The Competitive Advantage of Nations. New York: Free Press.

Prendergast, Renee. 1990. Scale of production and choice of technique in the engineering industries in developing countries. Journal of Development Studies 27, 72-88.

Qiu, Larry, D. and Wen Zhou. 2007. Merger waves: a model of endogenous mergers. Rand Journal of Economics 30, 214-226.

Spencer, Barbara, and James Brander. 1983. International R\&D rivalry and industrial strategy. Review of Economic Studies 50, 707-722.

Tabuchi, Takatoshi, Jacques-Francois Thisse, and Xiwei Zhu. 2018. Does technological progress magnify regional disparities? International Economic Review 59, 647-663.

Venables, Anthony. 1985. Trade and trade policy with imperfect competition: The case of identical products and free entry. Journal of International Economics 19, 1-19.

Wen, Lei, and Haiwen Zhou. 2020. Technology choice, financial sector and economic integration under the presence of efficiency wages. Open Economies Review 31, 95-112.

Wheeler, Christopher. 2006. Productivity and the geographic concentration of industry: The role of plant scale. Regional Science and Urban Economics 36, 313-330.

Zhou, Haiwen. 2004. The division of labor and the extent of the market. Economic Theory 24, 195-209.

Zhou, Haiwen. 2007. Oligopolistic competition and economic geography. Journal of Regional Science 47, 915-933.

Zhou, Haiwen. 2009. Population growth and industrialization. Economic Inquiry 47, 249-265.

Zhou, Haiwen. 2019. Coordination costs, market size, and the choice of technology. Frontiers of Economics in China 14, 131-148.

Zhou, Haiwen. 2021. Fixed costs and the division of labor. Annals of Economics and Finance 22, 63-81. 